\title{
Preparation and Aggregation-Induced Emission of New 1,3,5-Triazine-2,4,6-tricarboxamide with Liquid Crystal Properties
}

\author{
ABDULHAMID UMAR ${ }^{1,2}$ and MUSTAFFA SHAMSUDDIN ${ }^{1 *}$ \\ 'Department of Chemistry, Faculty of Science, Universiti Teknologi Malaysia, 81310 Johor Bahru, \\ Johor, Malaysia. \\ ${ }^{2}$ Adamawa State University Mubi, PMB 25 Mubi, Adamawa State, Nigeria. \\ ${ }^{*}$ Corresponding author E-mail: mustaffa @ kimia.fs.utm.my \\ http://dx.doi.org/10.13005/ojc/340405
}

(Received: May 02, 2018; Accepted: July 21, 2018)

\begin{abstract}
The combination of aggregation-induced emission (AIE) and liquid crystal properties generates solid-state efficient luminescent liquid crystal materials. Here in, we reported the synthesis of 1,3,5-triazine-2,4,6-tricarboxamide and utilized it as a supramolecular organic motif for the AIE-active liquid crystal material. The compound exhibits high-intensity emission maxima at 417 and $468 \mathrm{~nm}$ in the solid state with excitation at $254 \mathrm{~nm}$, whereas it shows weak emission in the solution phase. Also, this compound behaves as liquid crystalline material and shows columnar hexagonal mesophase with endothermic peaks at $73.4^{\circ} \mathrm{C}, 185.6^{\circ} \mathrm{C}$, and exothermic peaks were observed at $181.9^{\circ} \mathrm{C}$ and $66.1^{\circ} \mathrm{C}$ with focal conic fan shape texture. The thermal data showed that the compound is stable up to $200^{\circ} \mathrm{C}$.
\end{abstract}

Keywords: Luminescence, 1,3,5-Triazine-2,4,6-Tricarboxamide, Aggregation-induced emission, liquid crystal.

\section{INTRODUCTION}

Organic solid luminescent materials have been attracting particular attention due to their vast potential applications, in displays, optoelectronics, organic solar cells, organic light emitting diode (OLED) as well as in the field of sensing and imaging $^{1,2}$. Conventional solid organic molecules are known to exhibit strong $\pi-\pi$ stacking interactions due to their extended $\pi$-conjugation and planar structure.
This interaction promotes loss of excitation energy. Consequently, the molecules are poorly or non emissive in the solid state, even though they emit efficiently in solution. The phenomenon is called aggregation-caused quenching (ACQ). Although many attempts have been made to overcome the $A C Q$ effect, such as introductions of large cyclic species and dendritic wedges to Fluorophores, these approaches often led not only to complicated syntheses, but also undesired photophysical

This is an Open Access article licensed under a Creative Commons Attribution-Non Commercial-Share Alike 4.0 International License (https://creativecommons.org/licenses/by-nc-sa/4.0/), which permits unrestricted Non Commercial use, distribution and reproduction in any medium, provided the original work is properly cited. 
properties ${ }^{5,6}$. In 2001, Tang et al., reported an unusual phenomenon with silacyclopentadine (silole) derivatives that are non emissive in solution but become highly emissive upon aggregation. The phenomenon is termed aggregation-induced emission (AIE) ${ }^{7}$. Restriction of intramolecular rotation was identified as the mechanism for AIE effect in aggregate state ${ }^{8}$.

Recently, many attention has been focused on luminescent liquid crystals (LCs) organic materials ${ }^{9,10}$, due to their combination of light emission, supramolecular organization and broad technological applications such as organic light-emitting diodes, polarized organic lasers ${ }^{11}$ and sensors ${ }^{12}$. In spite of the unique properties of luminescent liquid crystal molecules, their syntheses remain challenging due to difficulty incorporating emissive functional group and liquid crystal properties. Also, many conjugated molecular emitters suffer aggregation-cause quenching effect leading to the quenching of fluorescence ${ }^{12}$. Therefore, the utilization of aggregation-induced emission could circumvent the ACQ effect since AIE molecules usually show strong emission in the solid or aggregate state. Although AIE-active LCs show promising prospects, the research is still rarely reported since the requirements for the LC and AIE characteristic are hard to fulfil at the same time in one single molecule. Here in, we report the first example of 1,3,5-triazine-2,4,6-tricarboxamide as an AIE-active liquid crystal (AIE-LC) bearing hydrophobic alkyl side chain with simple aromatic 1,3,5-triazine AIE core. It has been known that attaching either long alkyl/alkoxy groups to the AIE core creates light-emitting liquid crystal materials ${ }^{13}$.

\section{MATERIALS AND METHODS}

\section{General}

All chemicals were obtained from Aldrich and used as received without further purification unless otherwise stated. ${ }^{1} \mathrm{H}$-NMR spectra were recorded on a Bruker Ultra-Shield $400 \mathrm{MHz}$ spectrometer. Samples were dissolved in $\mathrm{CDCl}_{3}$ or $\mathrm{D}_{2} \mathrm{O}$ as solvent and chemical shifts are reported in $\mathrm{ppm}$. FT-IR spectra were recorded on a Perkin Elmer spectrometer in the range of $4000-400 \mathrm{~cm}^{-1}$ using $\mathrm{KBr}$ disk. Mass spectra were obtained using a Kratos MALDI-TOF mass spectrophotometer system. UV-Vis absorption spectrum was recorded on a Shimadzu UV-2600 spectrophotometer Photoluminescence spectrum was recorded on JASCO FR 8500 spectrophotometer. TGA was performed a Mettler Toledo tga/851e thermal analyser under nitrogen atmosphere at a heating rate of $10^{\circ} \mathrm{C} \mathrm{min}-1$. The liquid crystal properties were determined using differential scanning calorimetry (DSC) on a Mettler Toledo calorimeter model DSC822e at range of temperature of 25 to $200^{\circ} \mathrm{C}$. Throughout the DSC analysis, the sample was heated and cooled at the rate of $10^{\circ} \mathrm{C}$ $\mathrm{min}^{-1}$. Polarized optical microscopy (POM) was performed on a Leica DM2700 P model optical polarizing microscope equipped with a Linkam LTS420 hot-stage.

\section{Synthesis of 1,3,5-Triazine-2,4,6-Tricarboxylic acid (2)}

Triethyl-1,3,5-triazine-2,4,6-tricarboxylate 1 $(1.0 \mathrm{~g}, 3.36 \mathrm{mmol})$ was transferred into a $250 \mathrm{~mL}$ round bottom flask fitted with a Liebig condenser. Separately, $\mathrm{NaOH}(0.672 \mathrm{~g}, 16.8 \mathrm{mmol})$ was dissolved in $50 \mathrm{~mL}$ mixture of water-ethanol (1:1) to form a homogenous solution. The solution was then added dropwise to the triethyl-1,3,5-triazine-2,4, 6-tricarboxylate, and the resultant mixture was heated to reflux for $10 \mathrm{~h}$ while stirring. After cooling to room temperature, the $\mathrm{pH}$ of the resulting solution was adjusted to $\mathrm{pH} 2$ with $0.1 \mathrm{M} \mathrm{HCl}$ after which a white precipitate was obtained. It was then filtered, recrystallized in ice-cold water and dried to give a white powder solid. Yield: $0.7 \mathrm{~g}, 3.28 \mathrm{mmol}, 97 \%$. ${ }^{1} \mathrm{H} \mathrm{NMR}\left(400 \mathrm{MHz}, \mathrm{CDCl}_{3} \delta / \mathrm{ppm}\right): 10.68(\mathrm{~s}, 3 \mathrm{H}, \mathrm{OH})$. FTIR (KBr): 3447 (m), $1744(\mathrm{~s}), 1651$ (w), $1416(\mathrm{~m})$ $1248(\mathrm{~s}) 852 \mathrm{~cm}^{-1}(\mathrm{~m})$.

\section{Synthesis of 1,3,5-triazine-2,4,6-tricarbonyl trichloride (3)}

1,3,5-triazine-tricarboxylic acid 2 $(0.5 \mathrm{~g}, 2.35 \mathrm{mmol})$ was transferred into a $250 \mathrm{~mL}$ two-necked round-bottom flask and was treated under vacuum for $10 \mathrm{~min}$. before being flowed with nitrogen gas after which $40 \mathrm{~mL}$ DMF was added and stirred at $0^{\circ} \mathrm{C}$ for 1 hour. Then, oxalyl chloride (1 $\mathrm{mL}, 7.75 \mathrm{mmol}$ ) was added dropwise, and the resulting solution was stirred at room temperature overnight. The mixture was then heated for $2 \mathrm{~h}$ at $70^{\circ} \mathrm{C}$ to remove any excess oxalyl chloride before allowing it to cool to room temperature. The solvent was removed by heating at $90^{\circ} \mathrm{C}$ under reduced 
pressure and vacuum dried overnight to give a pale pink solid product. The obtained solid was used for further synthesis without purification.

\section{Synthesis of 1,3,5-triazine-2,4,6-tricarboxamide (5)}

1,3,4-triazinetricarbonyl trichloride 3 $(0.631 \mathrm{~g}, 2.35 \mathrm{mmol})$ was placed into a two-neck round bottom flask and was treated under vacuum for $10 \mathrm{~min}$. before being flowed with nitrogen gas. Then 1-aminododecane $(1.44 \mathrm{~g}, 7.76 \mathrm{mmol})$ was added dropwise, and the mixture was added with $50 \mathrm{~mL}$ dried chloroform, followed by the addition of triethylamine $(1.09 \mathrm{~mL}, 7.76 \mathrm{mmol})$. After the addition was completed, the reaction mixture was stirred overnight at room temperature, and the resulting mixture was filtered. The targeted product was successfully isolated using column chromatography with chloroform/methanol $50: 1$ as an eluent and subsequently evaporated and dried under inert condition by using vacuum pump under reduced pressure at room temperature to afford a white solid powder product. Yield: $0.87 \mathrm{~g}, 1.22 \mathrm{mmol}$, $52 \%$. ${ }^{1} \mathrm{H}$ NMR (400 MHz, $\mathrm{CDCl}_{3} \delta / \mathrm{ppm}$ ): 0.83-0.87 (t, $\left.\mathrm{J}=7.2 \mathrm{~Hz}, 9 \mathrm{H},-\mathrm{CH}_{3}\right), 1.22-1.35$ (overlapped, $54 \mathrm{H}$, $\left.-\mathrm{CH}_{2}\left(\mathrm{CH}_{2}\right) 10\right)$ 1.70-1.79 (m, 6H - $\left.\mathrm{CH}_{2}\right)$ 2.93-2.97 (t, J $\left.=8.0 \mathrm{~Hz}, 6 \mathrm{H}-\mathrm{NHCH}_{2}\right), 8.20(\mathrm{~s}, 3 \mathrm{H}, \mathrm{NH})$. FTIR (KBr): $3430(\mathrm{M}), 1630$ (s), 1585 (m), 1516 (w) 1475 (m), $1371(\mathrm{~m}), 1143$, (s) $835 \mathrm{~cm}^{-1}(\mathrm{~m})$ MS (MALDITOF): $\mathrm{m} / \mathrm{z} 753.5757\left[\mathrm{M}+\mathrm{K}^{+}\right]$observed, Calcd for $\mathrm{C}_{42} \mathrm{H}_{78} \mathrm{~N}_{6} \mathrm{O}_{3}: 753.5772\left[\mathrm{M}+\mathrm{K}^{+}\right]$.

\section{RESULTS AND DISCUSSION}

Scheme 1 illustrates the structures and the synthetic route to 1,3,5-triazine-2,4,6tricarboxamide (5). The target compound was synthesized by Schotten-Baumann amidation reaction ${ }^{14}$, starting with the base hydrolysis of triethyl-1,3,5-triazine-2,4,6-tricarboxylate 1 to afford 1,3,5-triazine-2,4,6-tricarboxylic acid 2 in good yield. Subsequently, compound 2 was subjected to acylation reaction with oxalyl chloride, $(\mathrm{COCl})_{2}$, in the presence of DMF resulting in the formation of 1,3,4-triazinetricarbonyl trichloride $\mathbf{3}$ which was then treated with 1-aminododecane in the presence of $\mathrm{CHCl}_{3} / \mathrm{Et}_{3} \mathrm{~N}$ to obtain 5 as white powder in $52 \%$ yield.

Based on the H-NMR spectra in Fig. 1 summarized in Table 1, the spectrum of precursor 1 dissolved in $\mathrm{CDCl}_{3}$ showed two signals corresponding to the methylene and methyl protons while the product 2 dissolved in $\mathrm{D}_{2} \mathrm{O}$ showed one signal belong to the hydroxyl proton. The chemical shift at 1.43-1.47 ppm (triplet, $9 \mathrm{H},=\mathrm{Ha}-\mathrm{CH}_{3}$ ) and 4.52-4.57 ppm (quartet, $6 \mathrm{H}, \mathrm{Hb}=-\mathrm{CH}_{2}$ ) of compound 1 disappeared in the spectrum of 2 due to cleavage of the ethyl group. Moreover, the appearance of peak at $10.68 \mathrm{ppm}$ (singlet, $3 \mathrm{H}, \mathrm{Hc}=\mathrm{OH}$ ) indicate the successful formation of compound 2 . It was further confirmed with FTIR as shown in Fig. 2a, by the disappearance of $\mathrm{C}-\mathrm{H}$ vibrations in the region $3000-2883 \mathrm{~cm}^{-1}$ indicating the cleavage of $\mathrm{OCH}_{2} \mathrm{CH}_{3}$ bond in compound 2 and the appearance of broad peak at $3447 \mathrm{~cm}^{-1}$ assigned to $\mathrm{O}-\mathrm{H}$ stretching vibration of 2 in Fig. $2 b^{15}$.

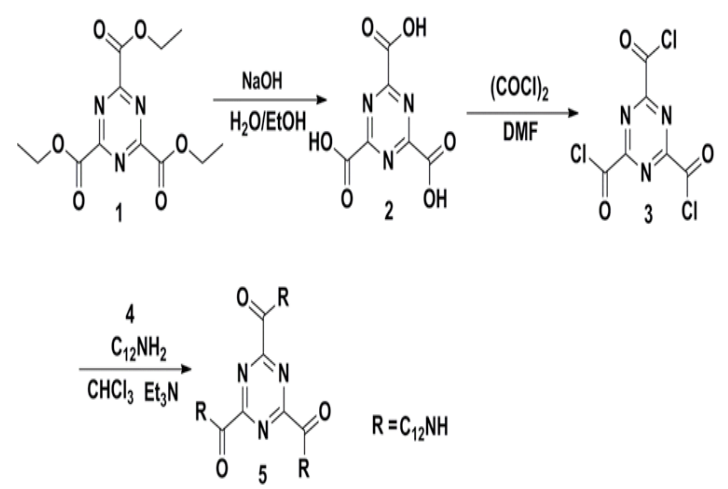

Scheme 1. Synthesis route for 1,3,5-Triazine-2,4,6-Tricarboxamide

Figure 3 showed ${ }^{1}$ HNMR spectra of the reactants 1 -aminododecane 4 and product 1,3,5-triazine-2,4,6-tricarboxamide 5 as summarized in Table 2 . The chemical shift of 1-aminododecane at 2.60-2.65 ppm (t, J $=8.0 \mathrm{~Hz}$, $2 \mathrm{H}-\mathrm{NHCH}_{2}$ ) in Fig. 3a was shifted to 2.93-2.97 (t, $\mathrm{J}=8.0 \mathrm{~Hz}, 6 \mathrm{H}-\mathrm{NHCH}_{2}$ ) in Fig. $3 b$ due to the successful transformation of acyl chloride group of 3 to form carboxamide group. Also the appearances of a broad peak at chemical shift $8.20 \mathrm{ppm}(\mathrm{s}, 3 \mathrm{H}$, $\mathrm{NH}$ ) in Fig. 3b indicates the attachment of alkyl side chains to triazine ring. Moreover, the formation of 5 was further confirmed by FTIR spectra in Fig. $2 c$ by the appearance of vibrational peaks at 3436 $\mathrm{cm}^{-1}$ attributed to $\mathrm{N}-\mathrm{H}$ stretching and $1558 \mathrm{~cm}^{-1} \mathrm{~N}-\mathrm{H}$ bending as well as $2849-2950 \mathrm{~cm}^{-1}$ assigned to $\mathrm{C}-\mathrm{H}$ stretching and $1475 \mathrm{~cm}^{-1} \mathrm{C}-\mathrm{H}$ bending, which show that the alkyl side chains was successfully bonded to the triazine ring. It was Further supported by MALDI-TOF-MS molecular weight $\mathrm{m} / \mathrm{z} 753.5757 \mathrm{Da}$ [M+K $\mathrm{K}^{+}$observed, $753.5772 \mathrm{Da}\left[\mathrm{M}+\mathrm{K}^{+}\right]$Calculated for chemical formula $\mathrm{C}_{42} \mathrm{H}_{78} \mathrm{~N}_{6} \mathrm{O}_{3}$. 
(a)

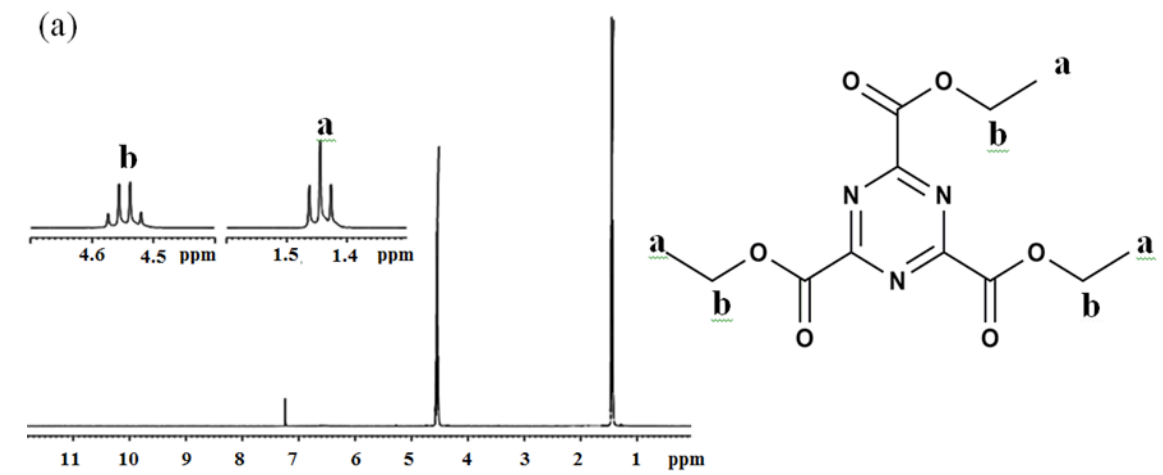

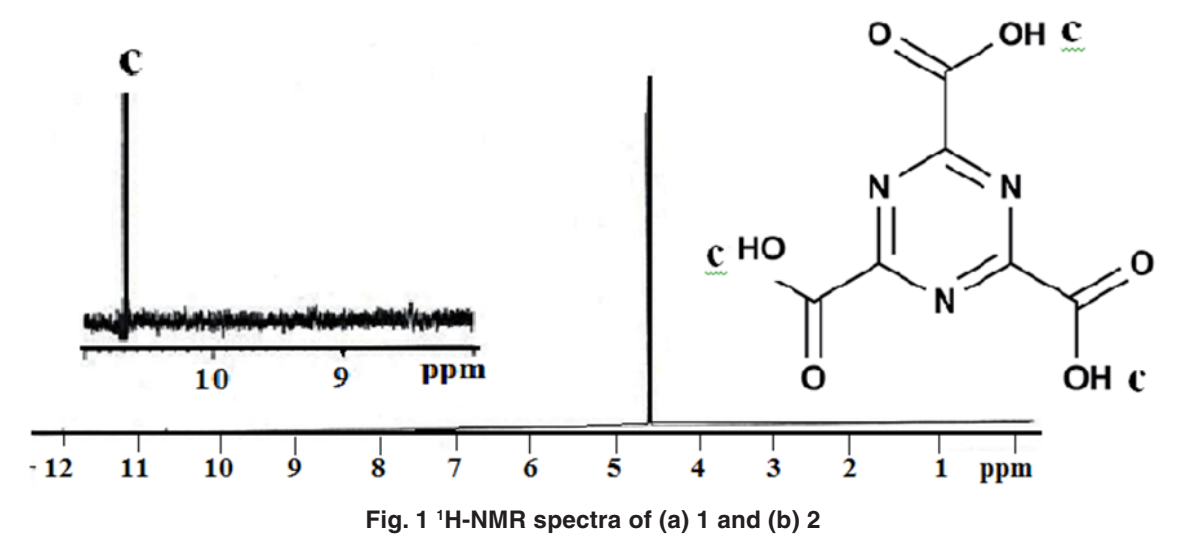

Table 1: ${ }^{1} \mathrm{H}-\mathrm{NMR}$ data for 1 and 2

\begin{tabular}{lccc}
\hline $\begin{array}{c}\text { Proton } \\
(\mathrm{H})\end{array}$ & \multicolumn{3}{c}{ Chemical shift (ppm) } \\
& 1 & & 2 \\
\hline a & $1.43-1.47$ & $(9 \mathrm{H})$ & - \\
b & $4.52-4.55$ & $(6 \mathrm{H})$ & - \\
$\mathrm{c}$ & - & & $10.68(3 \mathrm{H})$ \\
\hline
\end{tabular}

\section{Photoluminescent behaviour}

1,3,5-triazine-2,4,6-tricarboxamide exhibits fluorescent emission maxima centered at $417 \mathrm{~nm}$ and $468 \mathrm{~nm}$ on excitation at $254 \mathrm{~nm}$. The luminescent response was investigated in solid and solution. It shows weak fluorescent emission intensity in chloroform solution, in contrast, it gave strong emission intensity in the solid state as shown in Fig. 4a. Upon excitation at $365 \mathrm{~nm}$ with hand-held UV lamp, the solid powder gave blue emission, but when the solution of $\mathbf{5}$ was illuminated at $365 \mathrm{~nm}$, practically no emission was observed Fig. 4b. Furthermore, the luminescent behaviour was investigated using UV-Vis absorption in solid state and solution as shown in Fig. 4c. In solid state 5 exhibit intense broadened absorption bands from 250-800 $\mathrm{nm}$ red shifted with respect to absorption in solution, suggesting intermolecular charge transfer (CT) interactions due to formation of supramolecular J-aggregate. However, in chloroform solution, the broad intense absorption band collapsed suggesting dissolved molecular species and the decreased in intermolecular charge transfer (CT) interactions, which is evident by a blue shift observed and a sharp absorption band at $231 \mathrm{~nm}$ suggesting molecular isolated species.

The intense emission of $\mathbf{5}$ in solid could be due to aggregation-induced emission (AIE). And its AIE mechanism could be accounted for similar to the previous reports ${ }^{9,16}$. The plausible AIE mechanism is shown in Fig. 5. In contrast to the ACQ effect as a result of free intramolecular rotations along $\mathrm{C}-\mathrm{C}$ bonds, molecules with AIE properties exhibit strong fluorescent in the aggregate state, attributed to the restriction of intramolecular rotations. It was suggested that multiple non covalent interactions such as hydrogen bonding would stiffen the structure of the molecules upon aggregation hindering free intramolecular rotations $\mathbf{s}^{17,18}$.

It is proposed that in the solution state, 5 exist as isolated molecular species which undergo free 
intramolecular rotations along the amide units upon excitation, which may result in the loss of excitons energy leads to the quenching of the fluorescent emission intensity. However, in the aggregate or solid state, the free intramolecular rotations are restricted due to multiple intermolecular interactions which blocked the non radiative relaxation pathway resulting in the stronger fluorescent emission.

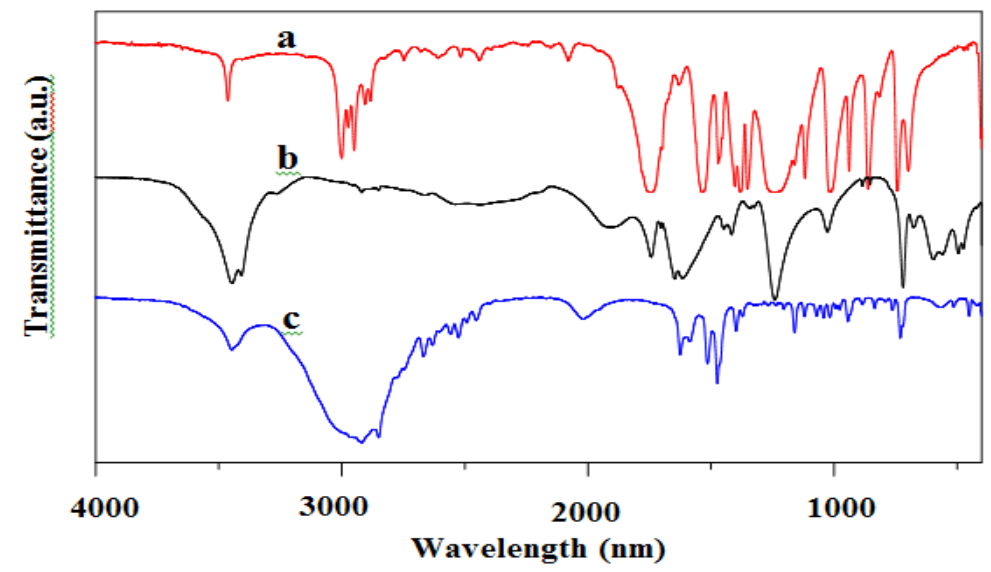

Fig. 2. FTIR spectra of compounds (a) 1 (b) 2 and (c) 5
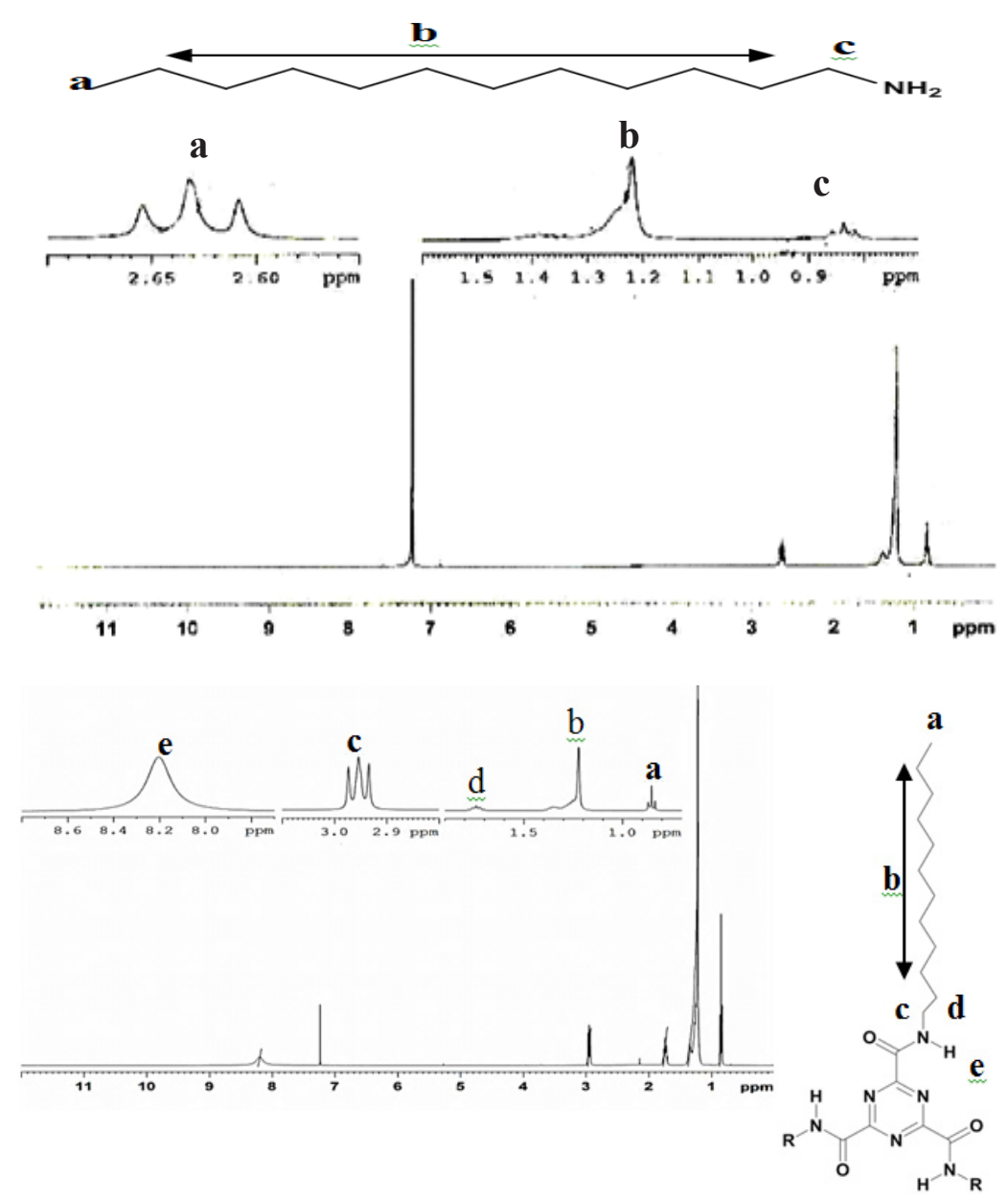

Fig. 3. ${ }^{1} \mathrm{H}-\mathrm{NMR}$ spectra of (a) 4 and (b) 5 
Table 2: ${ }^{1} \mathrm{H}-\mathrm{NMR}$ data for 4 and 5

\begin{tabular}{lcc}
\hline $\begin{array}{c}\text { Proton } \\
(\mathrm{H})\end{array}$ & 4 & 5 \\
\hline a & $0.77-0.86(3 \mathrm{H})$ & $0.83-0.87(9)$ \\
b & $1.29-1.41(20 \mathrm{H})$ & $1.22-135(54 \mathrm{H})$ \\
$\mathrm{c}$ & $2.60-2.65(2 \mathrm{H})$ & $2.93-2.97(6 \mathrm{H})$ \\
$\mathrm{d}$ & - & $1.70-1.79(6 \mathrm{H})$ \\
$\mathrm{e}$ & - & $8.20(3 \mathrm{H})$ \\
\hline
\end{tabular}

\section{Liquid crystal properties}

The liquid crystal behaviour was investigated using polarized optical microscopy (POM) and differential scanning calorimetry (DSC). The heating and cooling rate were $10^{\circ} \mathrm{C} \mathrm{min}^{-1}$. Upon cooling from its isotropic phase at $190^{\circ} \mathrm{C}$ to anisotropic texture the POM showed the appearance of focal conic fan-like texture a typical characteristic of hexagonal columnar mesophase $(\text { Colh })^{19}$, as shown
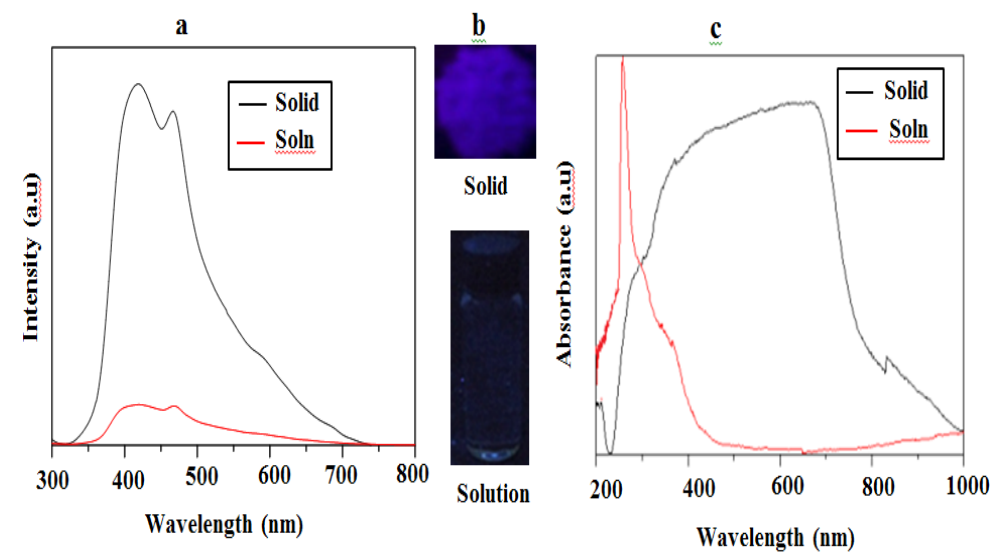

Fig. 4. (a) Emission spectra of 5 in solid and solution (b) Photograph of its emission in solid and solution under illumination of UV lamp (c) Absorption spectra in solid and solution<smiles>[2H]N([2H])C(=O)NC(=O)Nc1nc(C=C)nc(C(=O)NP)n1</smiles>

Free rotation in solution

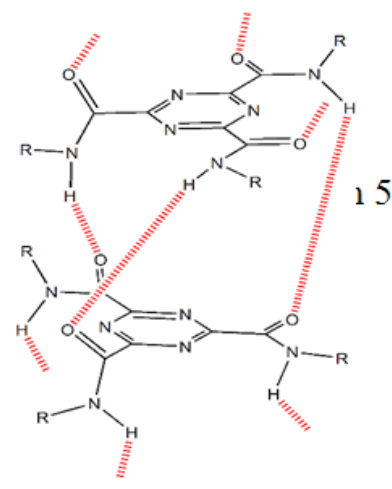

Restricted rotation in the aggregate state

Fig. 5. Plausible AIE mechanisms in 5

in Fig. 6a and b. The DSC thermogram displays two endothermic transitions at $73.4^{\circ} \mathrm{C}$ and $185.6^{\circ} \mathrm{C}$ upon heating from crystalline $(\mathrm{Cr})$ phase to isotropic (Iso) phase and two exothermic peaks at $181.9^{\circ} \mathrm{C}$ and $66.1^{\circ} \mathrm{C}$ when cooled from the isotropic to crystalline phase as shown in Fig. 6c. In addition, two crystalline modifications peaks were observed upon cooling $\left(\mathrm{Cr}\right.$ and $\mathrm{Cr} 1$ ) related to the crystallization process ${ }^{20}$.
We believed that the transition from the isotropic phase to crystal phase on cooling is accompanied by a reorganization of the molecule in which crystal structural modification is likely to occur.

\section{Thermal behaviour}

The thermogravimetric analysis (TGA) property of $\mathbf{5}$ has two identifiable weight loss stages as shown in Fig. 7. It starts in a temperature range 
of $200^{\circ} \mathrm{C}$ with a $1 \%$ weight loss corresponding to the organic structural collapse of the triazine ring and the alkyl chain. Above $200^{\circ} \mathrm{C}$, the compound showed gradual decrease in weight up to $95 \%$ and finally decomposed at $330^{\circ} \mathrm{C}$. Thus this thermal analysis data suggested that the compound is stable up to $200^{\circ} \mathrm{C}$.
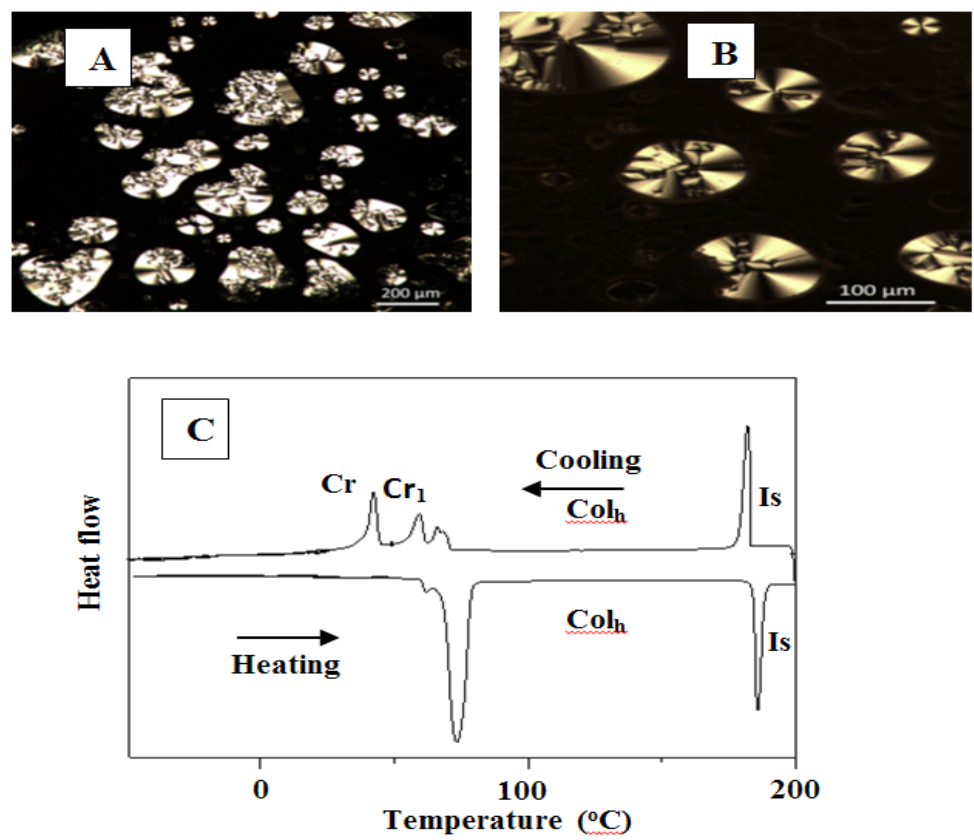

Fig. 6. POM images of 5 upon cooling from isotropic state (a) at $200 \mu \mathrm{m}$ (b) at $100 \mu \mathrm{m}$ and (c) DSC thermogram of 5 upon heating and cooling cycle

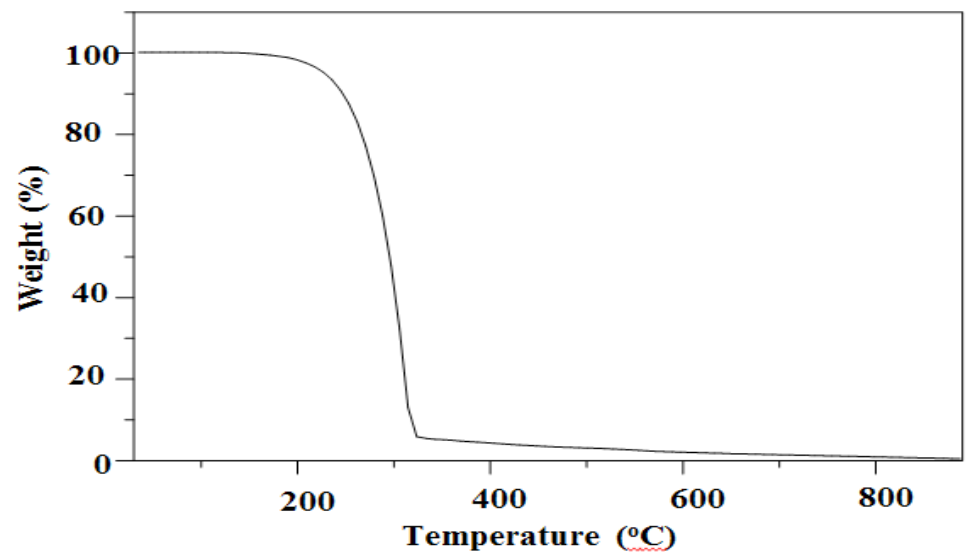

Fig. 7.TGA plot for 5

\section{CONCLUSION}

In summary, we successfully prepared and characterized AIE-active liquid crystal material based on 1,3,5-triazine-2,4,6-tricarboxamide. On the basis of the results obtained, the material was weakly emissive in solution but emit efficiently in the aggregate state, and formed columnar hexagonal LC phase with focal conic-fan shape texture in addition the molecule exhibit high thermal stability.
By combining the advantages of aggregation induce emission and liquid crystal properties such as long-range self-assembly and charge carrier mobility, make this material good candidate for optoelectronic applications.

\section{ACKNOWLEDGEMENT}

The authors would like to thank Universiti 
Teknologi Malaysia for the research facilities. AHU highly Acknowledged the Tertiary Education Trust
Fund (TETFUND) Nigeria and Adamawa State University, Mubi, Nigeria for the financial support.

\section{REFERENCES}

1. Gupta, V. K.; Singh, R. A. Aggregation-induced enhanced green light emission from a simple donor $-\pi-$ acceptor $(D-\pi-A)$ material: a structure-property relationship study. Faraday discussions., 2017, 196, 131-142.

2. Zhang, J. N.; Kang, H.; Li, N.; Zhou, S. M.; Sun, H. M.; Yin, S. W.; Zhao, N.; Tang, B. Z. Organic solid fluorophores regulated by subtle structure modification: color-tunable and aggregation-induced emission. Chem. Sci., 2017, 8, 577-582.

3. Carayon, C.; Fery-Forgues, S.2-Phenylbenzoxa zole derivatives: a family of robust emitters of solid-state fluorescence. Photochem. Photobiol. Sci., 2017, 7, 1020-35.

4. Xue, S.;Qiu, X.;Sun, Q.;Yang,W. Alkyl length effects on solid-state fluorescence and mechanochromic behaviour of small organic luminophores. J. Mater. Chem. C., 2016, 4, 1568-1578.

5. Yang, J. S.; Yan, J. L. Central-ring functionalization and application of the rigid, aromatic, and $\mathrm{H}$-shaped pentiptycene scaffold. Chem Comm., 2008, 13, 1501-12.

6. Hecht, S.; Fréchet, J. M. Dendritic encapsulation of function: applying nature's site isolation principle from biomimetics to materials science. Angew. Chem. Int. Ed., 2001, 40, 74-91.

7. Luo, J.; Xie, Z.; Lam, J. W.; Cheng, L.; Chen, H.; Qiu, C.; Kwok, H. S.; Zhan, X.; Liu, Y.; Zhu, D.; Tang, B. Z. Aggregation-induced emission of 1-methyl-1, 2, 3, 4, 5-pentaphenylsilole. Chem Comm., 2001, 18, 1740-1.

8. Hong Y. Aggregation-induced emissionfluorophores and applications. Methods and applications in fluorescence., 2016, 4(2), 022003.

9 Jing, H.; Lu, L., Feng, Y.; Zheng, J. F.; Deng, L.; Chen, E. Q.; Ren, X. K. Synthesis, Aggregation-Induced Emission, and Liquid Crystalline Structure of TetraphenylethyleneSurfactant Complex via Ionic Self-Assembly. J. Phys. Chem. C., 2016, 120(48), 27577-86.

10. Zhao, D.; Fan, F.; Cheng, J., Zhang, Y.; Wong, K.S.; Chigrinov, VG.; Kwok, H. S.; Guo, L.; Tang, B. Z. Light-Emitting Liquid Crystal Displays Based on an Aggregation-Induced Emission Luminogen. Adv. Opt. Mater., 2015, 3(2), 199-202.
11. Lam, J. W.; Kong, X.; Dong, Y.; Cheuk, K. K.; $\mathrm{Xu}, \mathrm{K}$.; Tang, B. Z. Synthesis and properties of liquid crystalline polyacetylenes with different spacer lengths and bridge orientations. Macromolecules., 2000, 14, 5027-40.

12 Yuan, W. Z.; Yu, Z. Q.; Lu, P.; Deng, C.; Lam, J. W.; Wang Z.; Chen E. Q.; Ma, Y.; Tang, B. $Z$. High efficiency luminescent liquid crystal: aggregation-induced emission strategy and biaxially oriented mesomorphic structure. J. Mater. Chem., 2012, 8, 3323-6.

13. Zhao D. Liquid Crystalline AIE Luminogens: Properties and Applications. In: AggregationInduced Emission: Materials and Applications Volume 2. Washington: American Chemical Society., 2016, 10, 151-171.

14. Matmin, J.; Yuliati, L.; Shamsuddin, M.; Lintang, H. O. Supramolecular Hydrogen Bonding Interactions of Novel 1, 3, 5-Benzenetricarbonyl Trisubstituted Alkyl for Anion Sensor Applications. Adv. Mater. Res., 2014, 925, 228-232 Trans Tech Publications.

15. Wade, Jr.; L. G. Organic Chemistry, 6thd Pearson Education Inc. New Jersey., 2006, 524-525.

16. Mei, J.; Hong, Y.; Lam.; J. W.; Qin, A.; Tang, Y.; Tang, B. Z. Aggregation-induced emission: the whole is more brilliant than the parts. $A d v$. Mater., 2014, 26(31), 5429-79.

17. Shyamal, M.; Maity, S.; Mazumdar, P.; Sahoo, G. P.; Maity, R.; Misra, A. Synthesis of an efficient Pyrene based AIE active functional material for selective sensing of 2, 4, 6-trinitrophenol. J. Photochem Photobiol A Chem., 2017, 342, 1-14.

18. HongY.;JackyW.Y.;Tang, B.Z. Aggregation-induced emission. Chem. Soc. Rev., 2011, 40, 5361-5388

19. Girotto E.; Eccher J.; Vieira, A. A.; Bechtold, I. H.; Gallardo H. Luminescent columnar liquid crystals based on 1, 3, 4-oxadiazole. Tetrahedron., 2014, 20, 3355-60.

20. Wróbel, S.; Chrusciel, J.; WierzejskaAdamowicz, M.; Marzec, M.; OssowskaChrusciel, D. M.; Legrand, C.; Douali, R. Ferroelectric liquid crystals composed of banana-shaped thioesters. In: FerroelectricsPhysical Effects. MickaA L. Ed., Rijeka: InTechOpen., 2011, 30, 429-448 